\title{
Consanguinity and pattern of congenital heart defects in Down syndrome in Kashmir, India.
}

\author{
Mohd Ashraf ${ }^{1}$, Reyaz A Malla ${ }^{3}$, Javed Chowdhary ${ }^{2}$, Mohd Irshad Malla ${ }^{3}$, Mymoona \\ Akhter $^{4}$, Ayaz Rahman $^{4}$, Saleem Javed ${ }^{5}$ \\ ${ }^{*}$ Corresponding author and Senior Resident, Dept. of Pediatrics, SKIMS Medical \\ College Srinagar, Phone No. : 09419011982, 019424313078 \\ ${ }^{2}$ Professor and Head Dept of Pediatrics at GB Pant Hospital, GMC Srinagar, \\ ${ }^{3}$ Senior Resident in Pediatrics, GMC Srinagar, ${ }^{4}$ Senior Resident GMC Srinagar. \\ ${ }^{5}$ Junior Resident SKIMS Medical College, Srinagar.
}

\begin{abstract}
Objective of our study was to ascertain the relation of consanguinity to Down syndrome (DS), and pattern of congenital heart defects (CHD) in DS. Setting: Department of Pediatrics, G B Pant Hospital, an associated hospital of Govt Medical College Srinagar. It was designed as a case control study. Fifty phenotypically DS patients aged between 0-12 years, attended our hospital from September 2007 to August 2008, were selected, formed the cases (Group I), and an equal number of patients, comparable in all respects but with-out DS or other apparent congenital malformations, were kept as controls (Group II). After detailed history and thorough examination, patients were enquired about the familial ties, and traditional values and a three generation pedigree was generated to ascertain consanguinity. All patients under-went echocardiography in addition to routine laboratory tests. The chi-square test was used to compare the proportions. Males constituted 27 and 26, while as females constituted 23 and 24 in group I and II respectively (p-value=0.841). Frequency of CHD among group I and II was 25(50\%) and $15(30 \%)$ respectively ( $p$-value $=0.041, \mathrm{OR}=2.3$ ). Pattern of $\mathrm{CHD}$ showed atrio-ventricular canal defects (AV canal defects) in 7 (28\%) in group I, and nil among group II ( $p$-value=0.024, OR=11.7), while as the commonest CHD in both groups was VSD. Among the group I consanguinity was present in $14(28 \%)$, while in group II consanguinity was present $17(34 \%)$ (p-value=0.51, OR=0.75). However, in group I with CHD, consanguinity was observed in 14 (56\%), and in group II with CHD consanguinity was observed in $3(20 \%)$ patients ( $p$-value 0.001 , OR 9.3). Fifteen (60\%) cases among the group I and $4(26.7 \%)$ cases among the group II were females with CHD (pvalue $=0.041, \mathrm{OR}=4.1)$. CHD is more common and severe among DS children who are products of consanguineous marriage, and CHD is more frequently seen in female DS children.
\end{abstract}

Keywords: Congenital heart defects, consanguinity, Down syndrome, echocardiography.

\section{INTRODUCTION}

Down syndrome (DS) is the most common genetic cause of developmental disabilities and mental retardation. It occurs in about 1 in 700 births, and is more common in males [1]. Most children are diagnosed on basis of phenotypic findings like, flat nasal bridge, poor muscle tone, a small head, upward slanting eyes, epicanthal folds, small ears, small mouth, dermographics (ulner loops, single palmer crease, and distal tri-radii), clinodactyly, large tongue, and a large space between toes (sandal gap). Index of suspicion is increased with presence of additional problems like congenital heart defects, gastrointestinal problems, hypothyroidism, mental retardation, developmental delays, leukemia, poor growth, dry skin, dental abnormalities, and atlantoaxial instability [2]. Approximately $40 \%$ of children with Down syndrome have congenital heart disease (CHD) [3], [4], which are responsible for early mortality in these children [5]. A high frequency of congenital heart disease occurs in children with Down syndrome from a population with widely prevalent consanguinity [6], [7]. Prevalence is higher in Asian countries, mostly seen in lower educational and socioeconomic groups, that are traditionally 
religious albeit declining with modernization. Morbidity increases significantly with inbreeding in many diseases studied in many countries [8].

The risk for birth defects in the offspring of first cousin matings has been increased to $5-8 \%$ compared to 2$3 \%$ in non-consanguineous marriages [9]. The prevalence of consanguinity reported in India is $36 \%$ and uncle-niece and first cousin are the more commonly occurring relationships in Indian population [10]. In spite of the available literature on consanguinity, there seemed a knowledge gap in India, regarding the consanguinity and DS. Since in Kashmir region of India consanguineous marriages are widely prevalent, an attempt was made to know the association of consanguinity and pattern of $\mathrm{CHD}$ in DS.

\section{METHODS:}

This hospital based case-control study, was conducted in the Department of Pediatrics, G. B. Pant Hospital, which is a referral hospital of Government Medical College Srinagar for children. Fifty four DS patients aged between 0-12 years, diagnosed on phenotypic appearance were randomly selected, over a period of one year, from September 2007-August 2008, irrespective of presence or absence any symptom, sign, X-ray chest or ECG abnormality to suggest CHD. But four patients died within 24 hours without echocardiographic evaluation, hence excluded from study. Similarly, equal number of non-syndromal, not malformed patients, matched in all respects, except appearing as DS, were selected using stratified random sampling method, during the same duration, to serve as controls. Simultaneously, any pre-term neonate or neonate with PDA, or any other child having chromosomal abnormality or metabolic disorder bearing an association with $\mathrm{CHD}$ was excluded from the study.
After a through clinical examination and detail history, a three-generation pedigree was generated in all patients to assign the degree of consanguinity. All patients were subjected for routine laboratory tests, like $\mathrm{CBC}$, serum electrolytes, renal function tests, blood sugar, chest X-ray, routine urine exam, ECG, and other relevant investigations. The diagnosis of DS was confirmed by chromosomal analysis of the peripheral blood lymphocytes. All patients with DS were placed in Group I, and rest of the patients formed the Group II. Group II patients were thus similar to Group I but without DS. Both cases and controls were subjected to two dimensional (2D) echocardiography. Echocardiographic pictures were recorded in standard parasternal long axis, short axis, apical 4-chamber, subcostal and suprasternal views. Colour doppler, and pulse and continuous wave Doppler were also performed on all patients. and results were compared. Presence of severity of any cardiac malformation was analyzed as per the recommendation of American society of echocardiography [11]. The results were analyzed and compared with 50 non-Down syndrome patients, in relation to consanguinity, and pattern of $\mathrm{CHD}$.

\section{RESULTS:}

Our study initially comprised of 54 DS patients, among which 4 died within 12 hours of hospital admission, leaving only 50 DS patients in group I, who were compared with 50 subjects as controls (group II). Most of patients in both groups were of 0-1 year of age. VSD turned out as commonest cardiac lesion in both groups. However, AV canal defects were more common in group I. Although, frequency of consanguinity was more in group II, but sever forms of CHD were more common in group I. Females outnumber the males as DS CHD cases. Detailed results are shown in following tables.

Table 1: Age distribution of the studied subjects

\begin{tabular}{|c|c|c|c|c|c|}
\hline \multirow{2}{*}{ Age } & \multicolumn{2}{|c|}{ No. of DS Patients } & \multicolumn{2}{|c|}{ Control Patients } & \multirow{2}{*}{$P$ value } \\
\hline & $\mathbf{N}$ & $\%$ & $\mathbf{N}$ & $\%$ & \\
\hline Neonate & 10 & 20.0 & 13 & 26.0 & \multirow{4}{*}{$\begin{array}{c}0.148 \\
\text { Non-Significant(NS) }\end{array}$} \\
\hline Infants & 21 & 42.0 & 28 & 56.0 & \\
\hline 1-5 Years & 13 & 26.0 & 5 & 10.0 & \\
\hline $6-12$ Years & 6 & 12.0 & 4 & 8.0 & \\
\hline Total & 50 & 100.0 & 50 & 100.0 & \\
\hline Mean \pm SD & \multicolumn{2}{|c|}{$1.97 \pm 3.03$} & \multicolumn{2}{|c|}{$1.29 \pm 2.76$} & 0.24 (NS) \\
\hline
\end{tabular}


Table 2: Frequency of CHD in Group I and II

\begin{tabular}{|l|l|l|l|l|l|}
\hline \multirow{2}{*}{ CHD } & \multicolumn{2}{|l|}{ Group I } & Group II & \multirow{2}{*}{ Result } \\
\cline { 2 - 6 } & N & \% & N & \% & \\
\hline Present & 25 & 50.0 & 15 & 30.0 & OR $=2.3$ \\
\hline Absent & 25 & 50.0 & 35 & 70.0 & $\begin{array}{l}\text { P }=0.041 \\
\text { (Sig.) }\end{array}$ \\
\hline
\end{tabular}

Table 3: Pattern of CHD among studied population

\begin{tabular}{|c|c|c|c|c|c|}
\hline \multirow[t]{2}{*}{ Pattern } & \multicolumn{2}{|c|}{ Group I } & \multicolumn{2}{|c|}{ Group II } & \multirow[t]{2}{*}{ Results } \\
\hline & $\mathrm{N}$ & $\%$ & $\mathrm{~N}$ & $\%$ & \\
\hline VSD & 12 & 48.0 & 6 & 40.0 & $\begin{array}{l}\text { OR=1.3; } \\
p=0.622\end{array}$ \\
\hline $\begin{array}{ll}\text { AV } & \text { canal } \\
\text { defect }\end{array}$ & 7 & 28.0 & 0 & 0.0 & $\begin{array}{l}\text { OR=11.7; } \\
p=0.024\end{array}$ \\
\hline $\begin{array}{l}\text { Secundum } \\
\text { ASD }\end{array}$ & 4 & 16.0 & 3 & 20.0 & $\begin{array}{l}\text { OR=0.8; } \\
p=0.747\end{array}$ \\
\hline PDA & 2 & 8.0 & 3 & 20.0 & $\begin{array}{l}\text { OR=0.3; } \\
p=0.267\end{array}$ \\
\hline PS & 0 & 0.0 & 2 & 13.3 & $\begin{array}{l}O R=0.1 \\
p=0.061\end{array}$ \\
\hline TOF & 0 & 0.0 & 1 & 6.7 & $\begin{array}{l}O R=0.3 \\
p=0.191\end{array}$ \\
\hline Total & 25 & 100.00 & 15 & 100.00 & $\begin{array}{l}X^{2}=14.010 \\
p=0.03\end{array}$ \\
\hline
\end{tabular}

Table 4: CHD as per gender in studied population

\begin{tabular}{|l|l|l|l|l|l|}
\hline \multirow{2}{*}{ Gender } & \multicolumn{2}{|l|}{ Group I } & Group II & Result \\
\cline { 2 - 6 } & $\mathrm{N}$ & $\%$ & $\mathrm{~N}$ & $\%$ & \\
\hline Male & 10 & 40.0 & 11 & 73.3 & OR=4.1; \\
\hline Female & 15 & 60.0 & 4 & 26.7 & $\mathrm{p}=0.041$ \\
\hline
\end{tabular}

Table 5: Consanguinity and gender in the studied subjects

\begin{tabular}{|c|c|c|c|c|c|}
\hline \multirow[t]{2}{*}{ Consanguinity } & \multicolumn{2}{|l|}{ Group I } & \multicolumn{2}{|l|}{ Group II } & \multirow[t]{2}{*}{ Result } \\
\hline & Number & Percentage & Number & Percentage & \\
\hline Present & 14 & $28 \%$ & 17 & $34 \%$ & \multirow{2}{*}{$\begin{array}{l}p=0.51 \\
O R=0.75 \\
(N S)\end{array}$} \\
\hline Absent & 36 & $72 \%$ & 33 & $66 \%$ & \\
\hline Total & 50 & 100.0 & 50 & 100.0 & 100 \\
\hline
\end{tabular}

Table 6: Correlation of Consanguinity with CHD in studied subjects

\begin{tabular}{|l|c|c|c|c|c|}
\hline \multirow{2}{*}{ Consanguinity } & \multicolumn{2}{|c|}{ Group I } & \multicolumn{2}{c|}{ Group II } & \multirow{2}{*}{ Result } \\
\cline { 2 - 6 } & $\mathbf{N}$ & $\mathbf{\%}$ & $\mathbf{N}$ & $\mathbf{\%}$ & \\
\hline Present & 14 & 56.0 & 3 & 20.0 & OR = 9.3 \\
$\mathrm{p}=0.001$ \\
(Significant)
\end{tabular}




\section{DISCUSSION}

The role of consanguinity in congenital malformations like DS and CHD has been studied by several authors from high consanguinity rate countries [12], [13], [14].

Striking feature of our study was that, all the 14 DS patients in group I, who were products of consanguineous marriage had CHD, and 7 (50\%) of these had AV canal defects, while as only 3 patients in group II, who were products of consanguineous marriage, had CHD, and none among these 3 had AV canal defects $(p<0.024)$. This important feature of our study implicates probable contributive effect of consanguinity for the occurrence and severity of CHD in DS (Group I). So it seems possible that consanguinity appears to be an associated risk factor for the severity and rate of CHD in DS. Although studies world over has observed an association between the consanguinity and CHD, [15], [16], but simultaneously has discouraged the association of consanguinity and DS [17], [18]. Analysis of our records showed that all the 4 DS patients who died within 12 hours of hospital admission were products of consanguineous marriage, which could possibly be because of an association between consanguinity and CHD severity in DS patients. These severe forms of CHD can lead to early fetal, or infant deaths among DS patients, who are products of consanguineous marriage, which supported by the evidence of association of bad obstetrical history (BOH) with consanguinity [19], [20].

Cardiac malformations are common among Down syndrome children and published studies have reported frequencies ranging from $35 \%$ to $65 \%$ (21], [22], [23], [24], [25], [26], which is quite comparable with our study that showed a frequency of $50 \%$ among the group I and 30\% among the group II $(p<0.041)$. Nevertheless, our study showed a more common occurrence of CHD among female DS children, as compared to non-DS children $(p<0.041)$, although CHD and DS as such individually are more common in males, which is in conformity with study by Park et al [27]. This implies that female DS children who are products of consanguineous marriage are more likely to suffer from CHD than non-DS patient. Our study showed VSD as most common lesion followed by $\mathrm{AV}$ canal defects, secundum ASD, and PDA .
In India, particularly in Kashmir region, the main reasons for consanguineous marriages are stronger family ties, the integrity of estates and age old traditional values. Although the most common form of consanguineous marriage in all major societies in India is between first cousins, which is strongly influenced by traditions. The unions like the marriage to mother's brother's daughter is the strongly preferred form of consanguineous union among South Indian Hindus (Rao and Inbaraj 1977), and all four types of first-cousin union, i.e. to father's brother's daughter, to father's sister's daughter, to mother's brother's daughter, and to mother's sister daughter, are arranged in South Asian Muslim communities [28]. In such a scenario the current debate in medical sciences is on the health implications of these consanguineous marriages. This marriage system has been reported as an important factor in the appearance of autosomal recessive diseases and congenital anomalies, including hydrocephalus, postaxial hand polydactyly and bilateral cleft lip cleft palate, bipolar disorders, depression, infant mortality, child deaths, spontaneous abortions and stillbirths [29]. From unpublished data of our hospital the high sib death rate among the consanguineous products than nonconsanguineous products in early infancy, could probably be because of autosomal recessive related inborn errors of metabolism. In spite of medical advancements, literacy rate and urbanization, still this family linked traditions are not able to be broken. Presence of family history of possible autosomal recessive condition may considerably increase the risk of offspring over the background risks of consanguinity. In such cases, the consanguineous couple can be tested for their carrier status and prenatal diagnosis when necessary. In a population with a high rate of consanguinity, like ours, the formulation of a structured public health and education programs, carry an immense importance, where a scientific and evidence based answers are offered to the consanguineous couples, since role of consanguinity as the etiological parameter is still in a primitive phase and further research is needed to satisfy the knowledge gap.

To conclude, our study revealed: DS children who are products of consanguineous marriage have severe forms of $\mathrm{CHD}$, and frequency of $\mathrm{CHD}$ is more among female DS children. This supposition should stimulate further research in this field to validate this hypothesis. 


\section{REFERENCES}

1. Torfs CP, Christianson RE. Anomalies in Down syndrome individuals in a large population-based registry. Am J Med Genet 1998; 77: 431-438.

2. Abott ME. New accessions in cardiac anomalies, pulmonary atresis of inflammatory origin, persistent ostrium primum with Mongolia idiocy. Internet AM Museums Bull 1924; 10: 11.

3. Rowe RD, Uchida IA. Cardiac malformations in Mongolism. Amer J Med 1961; 31: 728.

4. Stoll C, Alembic Y, Dolf B, Roth MP. Study of Down syndrome in 238,942 consecutive births. Ann Genet 1998; 41: 44-51.

5. Reller MD, Morris CD. Down syndrome affects results of surgical correlation of complete atrioventricular canal. Pediatric Cardiology 1992; 13: 80-84

6. Becker S, Al-Hakees Z, Molins C, Peterson R. Consanguinity and congenital heart disease in Saudi Arabia. Am J Med Genet 2001; 99: 8-13.

7. Teebi AS, Feraag TI. Genetic disorders among Arab populations, 1st ed. Oxford University Press, 1997, pp: $102-110$

8. Khlat $M$, Khoury $M$. Inbreeding and diseases: demographic, genetic, and epidemiologic perspectives. Epidemiol Rev. 1991; 13: 28-40

9. Magnus $\mathrm{P}$, Berg $\mathrm{K}$, Bjerkedal $\mathrm{T}$. Association of parental consanguinity with decreased birth weight and increased rate of early death and congenital malformation. Clin Genet 1985; 28: 342-445.

10. Nath A, Patil C, Naik VA. Prevalence of consanguineous marriages in rural community and its effects on pregnancy outcome. Indian Journal of Community Medicine 2004; 29: 41-43.

11. American Society of Echocardiography. Recommendations for continuous quality improvement in echocardiography. J Am Soc Echocardiogr 1995; 8: S1-28.

12. Wahab AA, Bener A, Teebi AS. The incidence patterns of Down syndrome in Qatar. Clin Genet 2006; 69: 3602.

13. Al-Gazali LI, Dawodu AH, Sabarinathan K, Varghese $M$. The profile of major congenital abnormalities in the United Arab Emirates (UAE) population. J Med Genet 1995; 32: 7-13.

14. Niazi MA, al-Mazyad AS, al-Husain MA, al-Mofada SM, al-Zamil MA, Khashogi TY, et al. Down's syndrome in Saudi Arabia: incidence and cytogenetics. Hum Hered 1995; 45: 65-9.

15. Jaber L, Merlob P, Bu X, Rotter JI, Shohat M. Marked parental consanguinity as a cause for increased major congenital malformation in an Israeli Arab community. Am J Med Genet 1992; 44: 1-6.

16. al Husain $M$, al Bunyan M. Consanguineous marriages in a Saudi population and the effect of inbreeding on prenatal and postnatal mortality. Ann Trop Paediatr. 1997; 17: 155-1560.

17. Rittler M, Liascovich R , López-Camelo J, Castilla E. Parental consanguinity in specific types of congenital anomalies Am J of Med Genet Part A, Volume 102 Issue 1, Pages $36-43$

18. Hammamy H, Al-Hakkak Z, Al-Taha S. Consanguinity and the genetic control of Down syndrome. Clin Genet 2001; 37: $24-29$

19. Verma IC, Prema A, Puri RK. Health Effects of Consanguinity in Pondicherry. Indian J Ped 1992; 29: 685-692.

20. Jain VK, Nalini P, Chandra R, Srinivasan S. Congenital malformations, reproductive wastage and consanguineous mating. Aust NZ J Obstet Gynaecol 1993; 33: 33-36.

21. P Venngopalen, AK Agarwal. Spectrum of congenital heart defects associated with Down syndrome in high consanguineous Omani population. Indian Pediatr 2003; 40: 398-403

22. Bower C, Ramsay JM. Congenital heart disease: a 10year cohort. J Pediatr Child Health 1994; 30: 414-418.

23. Freeman SB, Taft LF, Dooley KJ, Allran K, Sherman $\mathrm{SL}$, Hassold TJ, et al. Population- based study of congenital heart defects in Down syndrome. Am J Med Genet 1998; 80: 213-217.

24. Aynaci FM, Orhan F, Celep F, Karaguzel A. Frequency of cardiovascular and gastrointestinal malformations, leukemia and hypothyroidism in children with Down syndrome in Trabzon, Turkey. Turk J Pediatr 1998; 40: 103

25. Spahis JK. Wilson GN. Down syndrome: perinatal complications and counseling experiences in 216 patients. Am J Med Genet 1999; 89: 96-99.

26. Nazer J, Eaglin MA, Cifuentes L. Incidence of Down syndrome at a University Hospital Maternity of Chile. A 25-year record: 1972-1997. Rev Med Chill 1998; 126: 383-390.

27. Park C, Beat R, Matthews A, Zuberbuhler JR, Rowe $\mathrm{RD}$, Neelies $\mathrm{WH}$, Chenox C. Down syndrome with congenital heart malformation. Am J Dis Child 1997; 131: 29-33.

28. Bittles AH. Endogamy, consanguinity and community genetics. J Genet 2002; 81: 91-98.

29. RaoTSS, Asha MR, Sambamurthy K, Rao KSJ. Consanguinity: Still a challenge. Indian J Psychiatry 2009; 51: 3-5 